\title{
High mortality in lower salaried Norwegian men: the healthy worker effect?
}

\author{
Espen Dahl
}

\begin{abstract}
Study objective-This study aimed to examine whether the high mortality in lower salaried men in Norway was related to an inflow into this group of unskilled workers with high mortality.

Design-Individual information on occupation was derived from the 1970 and the 1980 censuses and linked to mortality data for the period $1980-5$ by the official, individual identification numbers.

Participants-The study population included Norwegian men aged 20-64 years in 1980. All men enumerated in the 1980 census (and who were registered in the 1970 census) within the two occupational groups, unskilled workers and lower salaried employees, were included.

Measurements and main results-The subjects were allocated to the two occupational groups according to the official Norwegian classification of socioeconomic status. Mortality was measured by standardised mortality ratios (SMR). The findings suggest that a fairly large number of unskilled workers with high mortality move into the lower salaried employee group. This transition produces a higher SMR in lower salaried employees and, simultaneously, an artificially but modestly lower SMR in unskilled workers. The difference in SMR between the two groups is thereby exaggerated by $44 \%$. The difference among the elderly was smaller.

Conclusion-Occupational mobility consistent with "the healthy worker effect" increases the SMR of lower salaried men and, at the same time, reduces slightly the SMR of unskilled workers.
\end{abstract}

f Epidemiol Community Health 1993; 47: 192-194

One peculiar finding in Norway in relation to health inequalities is the prevailing excess mortality in lower salaried men. ${ }^{12}$ Dahl and Kjærsgaard $^{2}$ analysed national data on socioeconomic status and mortality for the three periods $1960-5,1970-5$, and 1980-5. Lower salaried employees had standardised mortality ratios (SMRs) of 121,114 , and 123 respectively, which were the highest of all the employed socioeconomic groups in each period. In comparison, the SMRs of unskilled workers were 102,106 , and 113 , respectively.

Such an anomaly in the social distribution of mortality is not readily evident in Sweden ${ }^{3}$ or in England and Wales. ${ }^{4}$ It suggests that it is more risky to be a lower salaried employee than, for example, an unskilled worker. This is suprising since unskilled workers have worse working conditions and more behaviours that are bad for health, especially where smoking and exercise are concerned, than other occupational groups, including lower salaried employees. ${ }^{5-7}$

This finding suggests that health selection may be partly responsible. People working in physically demanding occupations, in poor working conditions, and in hazardous workplaces tend to shift to physically lighter jobs when their health fails, a phenomenon denoted "the healthy worker effect". ${ }^{8}$ To the extent that occupational class coincides with working conditions, this kind of health selection will also influence health inequalities between classes, and there is little doubt that unskilled workers have poorer working conditions than lower salaried employees. ${ }^{7}$ It is not likely, however, that such a movement of workers will reach far "up" the occupational hierarchy-for example employees on higher salaries. Segmented labour markets and high fences surrounding higher status jobs prevent such far reaching leaps.

The question raised here is whether the persistently high SMR in lower salaried men is attributable to health related, intragenerational, occupational mobility-that is the inflow of unhealthy, unskilled, manual workers into lower salaried employment. If this is the case, the extent to which mobility contributes to an underestimation of the SMR in unskilled male workers should be determined.

The concept of "the healthy worker effect" originated in occupational medicine. ${ }^{89}$ In general, it refers to health selection by entrance to and exit from the workforce or particular occupations. These processes have several effects. If exit from the workforce is health related and is concentrated in the lower socioeconomic classes, it may lead to artificially low class gradients in (ill) health among the employed. The effect may also lead to an underestimation of the damaging health effects of physically demanding work, and, correspondingly, to overestimation of the health risks of light physical jobs. Perhaps this effect is most pronounced in elderly employees since they may be in greater need of less physically demanding work.

The kind of health related mobility described by the healthy worker effect differs from the ordinary health selection hypothesis in at least two ways. Firstly, the healthy worker effect tends to mask health inequalities produced by socioeconomic factors rather than exaggerating them. ${ }^{10}$ Secondly, as fas as movement from physically heavy to light occupations is concerned, it addresses mobility on the horizontal plane and not on the vertical. ${ }^{11}$ 
Available empirical evidence suggests that the healthy worker hypothesis is a plausible phenomenon. The British OPCS longitudinal study provides evidence of a healthy worker effect generated by class and health related exit from the workforce. In a five year follow up on mortality, Fox et $a l^{12}$ showed, among other things, that the class gradient grew steeper with the duration of the follow up, thus indicating that the effects on mortality of disproportionate class exit wore off as time passed. The hypothesis was confirmed by a later 10 year follow up. ${ }^{13}$ Here, a steeper class gradient was found for the 1976-81 period than for the 1971-5 period.

More pertinent, however, is a Swedish study by Östlin. ${ }^{14} \mathrm{He}$ examined movements of unhealthy subjects from physically heavy work to physically light work. He showed that because of health selection the prevalence of morbidity in physically light occupations was overestimated by $15-50 \%$ for men and by $9-24 \%$ for women. ${ }^{14} 28$

\section{Methods}

The data set was provided by the National Central Bureau of Statistics. The prime sources were the Mortality Registry and the censuses of 1970 and 1980. Individual information on occupation recorded by the two censuses was linked to subsequent mortality for the period $1980-5$ by means of the official identification numbers.

All men aged $20-64$ years in 1980, grouped as unskilled workers and lower salaried employees, and within the mobility group were included in the study. The number of men and the number of deaths for the entire age span and for the elderly are shown in table I.

Table I Number of men and number of deaths (1980-5) by social group and age group

\begin{tabular}{|c|c|c|c|c|}
\hline & \multicolumn{4}{|c|}{ Age group } \\
\hline & \multicolumn{2}{|c|}{$\overline{20-64}(y)$} & \multicolumn{2}{|c|}{$50-64(y)$} \\
\hline & No & Deaths & $\overline{N o}$ & Deaths \\
\hline $\begin{array}{l}\text { Unskilled workers } \\
\text { Lower salaried }\end{array}$ & 287752 & 6605 & 76751 & 4596 \\
\hline $\begin{array}{l}\text { employees }{ }^{\star} \\
\text { Mobility group } 1 \rightarrow 2\end{array}$ & $\begin{array}{r}42104 \\
7373\end{array}$ & $\begin{array}{l}941 \\
225\end{array}$ & $\begin{array}{l}9720 \\
2258\end{array}$ & 684 \\
\hline
\end{tabular}

The reference population for calculation of the SMR includes both previously and currently employed men. In both the censuses, people who had worked at least 500 hours during past year were counted as employed. The age span was divided into nine, five year intervals ranging from 20-24 years of age to $60-64$ years of age. The 50-64 year age band comprises three age groups.

The Norwegian classification of socioeconomic status was used to aggregate the occupations into broader occupational groupings. ${ }^{15}$ Occupations in both groups require about the same low mean level of education. The group of employees on lower level salaries includes occupations such as shop assistant and waiter, while unskilled workers typically includes general, manual labourers such as factory workers and dockers.

\section{Results}

Table II shows SMRs for the two socioeconomic groups, the SMR for the mobility group, and the changes in the SMR produced by the transition in
Table II Standardised mortality ratio (SMR) in unskilled workers and lower salaried employees, SMR of movers and SMR effects of the transitions. Men aged 20-64 years and 50-64 years.

\begin{tabular}{lcc}
\hline & \multicolumn{2}{c}{ Age group } \\
\cline { 2 - 3 } & $20-64$ y & $50-64 y$ \\
\hline Unskilled workers & 92 & 85 \\
Lower salaried employees & 101 & 101 \\
Difference $1-2$ after mobility & -9 & -16 \\
Mobility group $1 \rightarrow 2$ & 108 & 109 \\
Effect on 1 when $1 \rightarrow 2$ included & 1 & 1 \\
Effect on 2 when $1 \rightarrow 2$ removed & -3 & -2 \\
Result for 1 & 93 & 86 \\
Result for 2 & 98 & 99 \\
Difference 1-2 before mobility & -5 & -13 \\
\hline
\end{tabular}

two age groups. The left column in table II shows that lower salaried employees have a higher SMR than unskilled workers after inflow of unskilled workers has taken place, that is by the classification of the 1980 census. The group that moved from unskilled work to lower salaried employment has a larger SMR than the two socioeconomic groups in question. Thus, removing it from the lower salaried employment group results in a fall in SMR of three. Conversely, including it in the group of unskilled workers raises the SMR here by one. The result of this reconstruction of the 1970 classification is that the difference in SMR between the two groups narrows by four. Put in other words, movement of unskilled workers to lower salaried employment during 1970-80 increases the difference in the SMR between the two groups by $44 \%$. Lower salaried employees, however, still have the highest SMR of the socioeconomic groups in employment.

The right column in table II gives the results for elderly employees. The SMR differences between the two socioeconomic groups in this age group are larger than for the whole age range because of the lower SMR of unskilled workers. The healthy worker effect works in the same direction as for the entire age span but is less marked, especially in relative terms.

\section{Discussion}

Mobility consistent with the healthy worker effect seems to occur in Norway. Through the inflow of unskilled workers with a high SMR, the resultant SMR of lower salaried employees is increased. At the same time the SMR of unskilled workers is slightly reduced. The transition increases the SMR difference between these two groups from 5 to 9 , or by $44 \%$. This result agrees with other evidence on the healthy worker effect referred to above. Contrary to expectations, however, the healthy worker effect was less noticeable in the elderly than in the entire age span.

An obvious weakness of the data is that they cannot ascertain whether mobility is conditioned by (ill) health or by social forces. We cannot rule out the possibility that ill health strikes because of mobility itself. The (perceived) stressfull event of changing job and class may trigger premature deaths. ${ }^{16}$ In addition, 10 years may be too short for a proper consideration of the healthy worker effect. If anything, the effect is probably underestimated. However, the data are from a period characterised by comprehensive structural mobility. Census data from 1970 and 1980 show that the fraction of unskilled workers has shrunk from $35 \cdot 8-29 \cdot 2 \%$, while the percentage of lower sala- 
ried employees has remained stable at $4-5 \% .^{2}$ Thus, the data cover a period in which the healthy worker effect had fairly favourable conditions in which to operate.

Since lower salaried employees still have the highest SMR of all the socioeconomic groups in employment, there are obviously forces that add to the healthy worker effect. Very likely, one contributing factor is the excess mortality of waiters. ${ }^{1}$ Thus, to account for the high remaining SMR of lower salaried employees requires identification of the selective or social circumstances underlying the high SMR of waiters.

This finding has relevance for previous results on selection and health inequalities. Dahl and Kjærsgaard ${ }^{17}$ found that intragenerational occupational mobility increased the resultant socioeconomic inequality in SMRs by $8 \cdot 8 \%$ (as measured by the variation coefficient). This increment was solely due to the impact of lower salaried employees. The present finding suggests that part of this increment is attributable to the healthy worker effect; it is the result of horizontal and not vertical mobility. On the basis of these results, the contribution of the healthy worker effect to the increment in SMR inequality is estimated to be $5 \cdot 5 \%$. This leaves only $3.3 \%$ of the resultant inequality in SMR caused by health selection to be accounted for by ordinary vertical health selection. (The absolute values of the variation coefficients (C) are as follows: before health selection; $\mathrm{C}=13 \cdot 79$, after horizontal+vertical health selection; $C=15 \cdot 12$, after vertical selection; $C=14 \cdot 29$.)

Contrary to the hypothesis, the healthy worker effect was less pronounced in elderly employees-those aged 50-64 years. At the same time the SMR differences between unskilled workers and lower salaried employees were distinctly larger for the elderly than for the total age span. This was primarily a result of the persistently low SMR of unskilled workers. One plausible interpretation is that elderly unskilled workers in poor health "prefer" to leave the labour market, for example as disability pensioners, rather than join the group of lower salaried employees. In a previous report, clear evidence was found of health related movement out of the work force in unskilled workers. ${ }^{18}$

The healthy worker effect may be even stronger for inequality in morbidity than in mortality. The principal causes of death, such as cancer and violent death, seem to strike so quickly that there is little opportunity for occupational mobility. ${ }^{19}$ The spectrum of illness is dominated by musculoskeletal, cardiovascular, and mental illnesses, and by injuries. ${ }^{6}$ The chronic nature of the first three of these illnesses suggests that they have a high potential for inducing a healthy worker effect and thereby cause serious bias in the soical distribution of morbidity.

The evidence shows that occupational mobility conforming to the healthy worker effect accounts for part of the excess mortality (SMR) of lower salaried men in Norway and produces simultaneously an artificially but only slightly lower SMR in unskilled male workers. The healthy worker effect is less pronounced in elderly employees than for the total age group.

I am indebted to Jon Ivar Elstad and Dag Hofoss for valuable comments on previous versions of this paper.

1 Borgan JK, Kristofersen LB. Dodelighet i yrker og sosiookonomiske grupper 1970-1980 (Mortality in occupations and socioeconomic groups). Oslo: Central Bureau of Statistics, 1986

2 Dahl E, Kjærsgaard P. Trends in socioeconomic mortality differentials in post-war Norway-evidence and interpretations. Sociology of Health and Illness, 1993 (in press)

3 Lundberg $O$. Den ojämlika ohälsam. Om klass- och könsskillnader $i$ sjuklighet (The unequal ill-health. On class-and gender differentials in morbidity). Stockholm: University of Stockholm, 1990.

4 Whitehead $\mathrm{M}$. The health divide: inequalities in health in the 1980s. London: The Health Education Council, 1987.

5 Botten G, Bjerkedal T. Ulikheter i helsevaner i Norge 1985 (Inequalities in health-related habits in Norway 1985). Tidsskr Nor Lagerforen 1988; 108: 157-62.

6 Health Survey 1985. Oslo: Central Bureau of Statistics, 1987.

7 Health Survey 1985. Oslo: Central Bureau of Statistics, 1987 . Survey of level of

8 Carpenter LM. Some observations on the healthy worker effect. Br f Ind Med 1987; 44: 289-91.

9 Wen CP, Tsai SP, Gibson RL. Anatomy of the healthy worker effect: a critical review. $\mathcal{f}$ Occup Med 1983; 25 283-9.

10 Stern J. Social mobility and the interpretation of social class mortality differentials. fournal of Social Policy 1983; 12 27-49.

1 Sorokin PA. Social and cultural mobility. New York: The Free Press, 1959.

12 Fox AJ et al. Selection and mortality differentials. F Epidemio Community Health 1982; 36: 69-79.

13 Fox AJ et al. Social class mortality differentials: artefact, selection or life circumstances. $\mathcal{F}$ Epidemiol Community Health 1985; 39: 1-8.

14 Östlin P. Occupational career and health. Methodological considerations on the healthy worker effect. Uppsala: University of Uppsala, 1988.

15 Album D. Standard for inndeling etter sosiookonomisk status (Standard for socioeconomic classification). Standarder Otandard for socioeconomic classification). Standarder Norsk statistikk no 5 .

16 Dohrenwend BS, Dohrenwend BP (eds). Stressful life events: their nature and effects. New York: John Wiley \& Sons, 1974. their nature and effects. New York: John Wiley \& Sons, 1974 Dahl E, Kjærsgaard P. Social mobility and inequality in
mortality-an assessment of the health selection hypothesis. European fournal of Public Health, 1993; 3: 245-53.

18 Dahl E. Social inequalities in health-the role of the healthy worker effect. Soc Sci Med, 1993; 36: 1077-86.

9 Blane D. An assessment of the Black report's explanations of health inequalities. Sociology of Health and Illness 1985; 7 437-45. 